LA W RENCE LIVERMORE NATIONAL LABORATORY

Performance Analysis of OccurrencesJanuary 1 , 2011-December 31, 2011

M. Ludwig

March 19, 2012 
This document was prepared as an account of work sponsored by an agency of the United States government. Neither the United States government nor Lawrence Livermore National Security, LLC, nor any of their employees makes any warranty, expressed or implied, or assumes any legal liability or responsibility for the accuracy, completeness, or usefulness of any information, apparatus, product, or process disclosed, or represents that its use would not infringe privately owned rights. Reference herein to any specific commercial product, process, or service by trade name, trademark, manufacturer, or otherwise does not necessarily constitute or imply its endorsement, recommendation, or favoring by the United States government or Lawrence Livermore National Security, LLC. The views and opinions of authors expressed herein do not necessarily state or reflect those of the United States government or Lawrence Livermore National Security, LLC, and shall not be used for advertising or product endorsement purposes.

This work performed under the auspices of the U.S. Department of Energy by Lawrence Livermore National Laboratory under Contract DE-AC52-07NA27344. 


\section{Performance Analysis of Occurrences January 1, 2011-December 31, 2011}

LLNL-AR-

January 31, 2012

Performance Analysis and Reporting Section

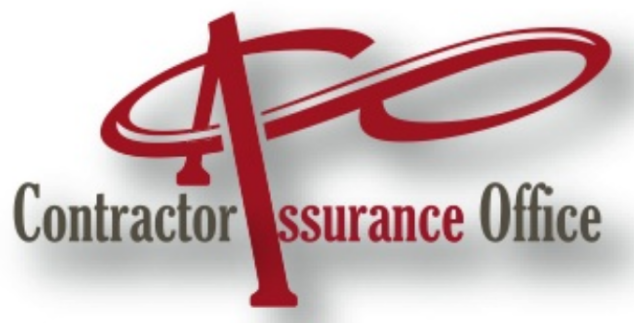




\section{Disclaimer}

This document was prepared as an account of work sponsored by an agency of the United States government. Neither the United States government nor Lawrence Livermore National Security, LLC, nor any of their employees makes any warranty, expressed or implied, or assumes any legal liability or responsibility for the accuracy, completeness, or usefulness of any information, apparatus, product, or process disclosed, or represents that its use would not infringe privately owned rights. Reference herein to any specific commercial product, process, or service by trade name, trademark, manufacturer, or otherwise does not necessarily constitute or imply its endorsement, recommendation, or favoring by the United States government or Lawrence Livermore National Security, LLC. The views and opinions of authors expressed herein do not necessarily state or reflect those of the United States government or Lawrence Livermore National Security, LLC, and shall not be used for advertising or product endorsement purposes.

This work performed under the auspices of the U.S. Department of Energy by Lawrence Livermore National Laboratory under Contract DE-AC52-07NA27344. 


\section{Table of Contents}

1.0 Comparison with DOE and NNSA in the Number and Types of Occurrences Reported 4

2.0 Occurrence Reporting Group Comparison ..................................................................... 7

3.0 Occurrence Significance Category Comparison With Other DOE Sites ..................... 9

4.0 Occurrences by Principal Directorate ........................................................................11

5.0 Summary of LLNL Occurrences by Reporting Criteria Group ...................................13

6.0 Summary of LLNL Occurrences by Significance Category (SC) .................................17

7.0 Below-ORPS (Site) Reportable Events .................................................................. 18 
This report documents the analysis of the occurrences during the period January 1, 2011 through December 31, 2011. The report compares LLNL occurrences by reporting criteria and significance category to see if LLNL is reporting occurrences along similar percentages as other DOE sites. The three-year trends are analyzed. It does not include the analysis of the causes or the lessons learned from the occurrences, as they are analyzed separately.

\subsection{Comparison with DOE and NNSA in the Number and Types of Occurrences Reported}

The number and types of occurrences that LLNL reports to DOE varies over time. This variation can be attributed to normally occurring changes in frequency; DOE's or LLNL's heightened interest in a particular subject area; changes in LLNL processes; or emerging problems. Since all of the DOE sites use the same reporting criteria, it is helpful to understand if LLNL is consistent with or diverging from reporting at other sites. This section compares the normalized number of occurrences reported by LLNL and other DOE sites.

In order to compare LLNL occurrence reports to occurrence reports from other DOE sites, we normalized (or standardized) the data from the sites. DOE sites vary widely in their budgets, populations, and scope of work and these variations may affect reporting frequency. In addition, reports are required for a wide range of occurrence types, some of which may not be applicable to all DOE sites. For example, one occurrence reporting group is Group 3, Nuclear Safety Basis, and not all sites have nuclear operations. Because limited information is available for all sites, the sites were normalized based on best available information. Site effort hours were extracted from the DOE Computerized Accident Incident Reporting System (CAIRS) and used to normalize (or standardize) the number of occurrences by site. Effort hours are those hours that employees normally work and do not include vacation, holiday hours etc. Sites are responsible for calculating their effort hours and ensuring entry into CAIRS.

Out of the 30 DOE sites that reported occurrences into ORPS during January 2011 through December 2011, 28 had effort hours available in CAIRS. Two sites had not submitted effort hours data to CAIRS as of the time data was pulled for this report. In those two cases, third quarter data was used as an estimate of fourth quarter data. The use of estimated data may introduce minor errors in the average, median, and Pearson calculations. Using the effort hours and the frequency of occurrences by site, a rate of occurrence frequency per 100 FTE workers was calculated. This rate is similar to the injury/illness frequency rate: the number of injury/illness cases per 100 FTE workers.

To validate that this rate was appropriate to use, we compared the effort hours and the frequency of occurrences by site to determine if a relationship exists between the two, e.g. the more effort hours a site has, the more occurrences they tend to have. This hypothesis was tested using the Pearson Correlation Coefficient Test. The correlation coefficient measures the strength of the linear relationship between effort hours and occurrence frequency. The Pearson Correlation Coefficient Test will determine if the true correlation coefficient is equal to zero (no relationship exists), or if the correlation coefficient is not equal to zero (a relationship exists). Values approaching 1.00 show a more positive correlation. Simple linear regression was also used to 
display a trend line and to test if a one-way relationship exists between effort hours predicting the number of occurrences a site will have.

Using the Pearson Correlation test, for the NNSA sites, effort hours and the number of occurrences are significantly and positively correlated with a correlation coefficient of 0.90 , as was also seen in the previous report (correlation coefficient of 0.67). All DOE sites are positively correlated with a coefficient of 0.85 . As the effort hours increase, so does the number of occurrences and vice versa. Based on the results of the simple linear regression, effort hours were found to predict the number of occurrences.

Figure 1 compares 30 DOE sites by the number of occurrences per site. This figure shows LLNL as the seventh highest site, in number of occurrences. 
Figure 1 - Occurrence Count by all DOE Sites Reporting to ORPS

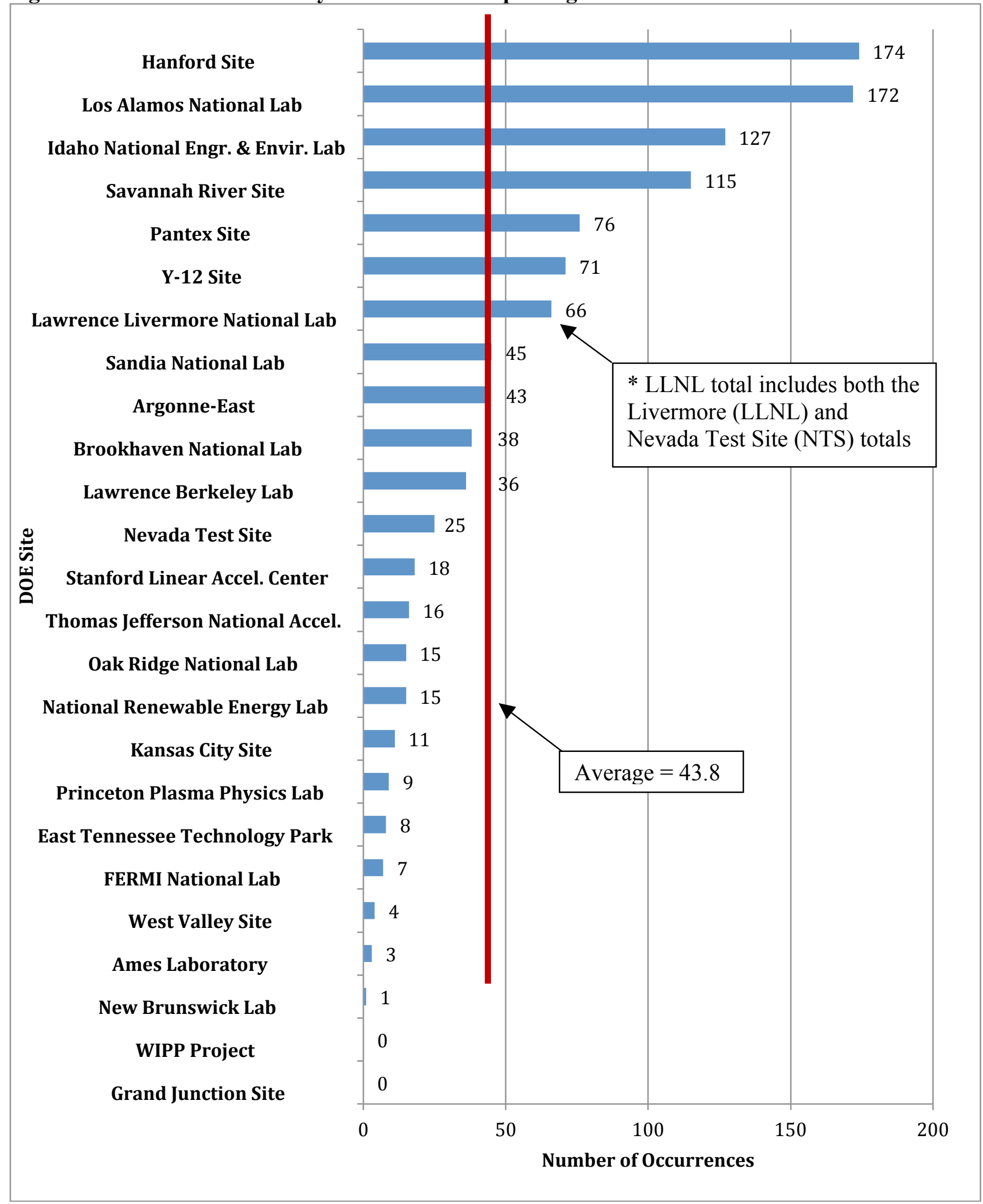


Using the effort hours reported by the NNSA sites reporting to CAIRS, we analyzed the normalized number of occurrences per NNSA site to identify if LLNL is reporting differently than other similar sites. Of these sites, LLNL has the fourth highest effort hours for the period January 1, 2011 through December 31, 2011. This analysis indicates that LLNL's rate of 1.46 occurrences per 100 FTE workers is slightly higher than the DOE median rate of 0.64 , and slightly lower than the NNSA median rate of 1.65. LLNL's rate of occurrences was slightly higher than in the previously analyzed 12-month period, when the LLNL rate was 1.02. LLNL's occurrence report rate is within the range of expected values, as displayed in Figure 2.

Figure 2 is a scatter graph that displays NNSA site effort hours on the $\mathrm{x}$-axis by the number of occurrences reported on the y-axis. Observationally, this figure shows that effort hours and the frequency of occurrences have a positive relationship: an increase in effort hours will result in an increase in occurrences, and vice versa. The trend line, shown in red in Figure 2 is a result of a simple linear regression. This method fits a line to the plotted data to display the relationship. LLNL has consistently been below the trend line in previous reports.

Figure 2 - Occurrence frequency by effort hours for NNSA sites

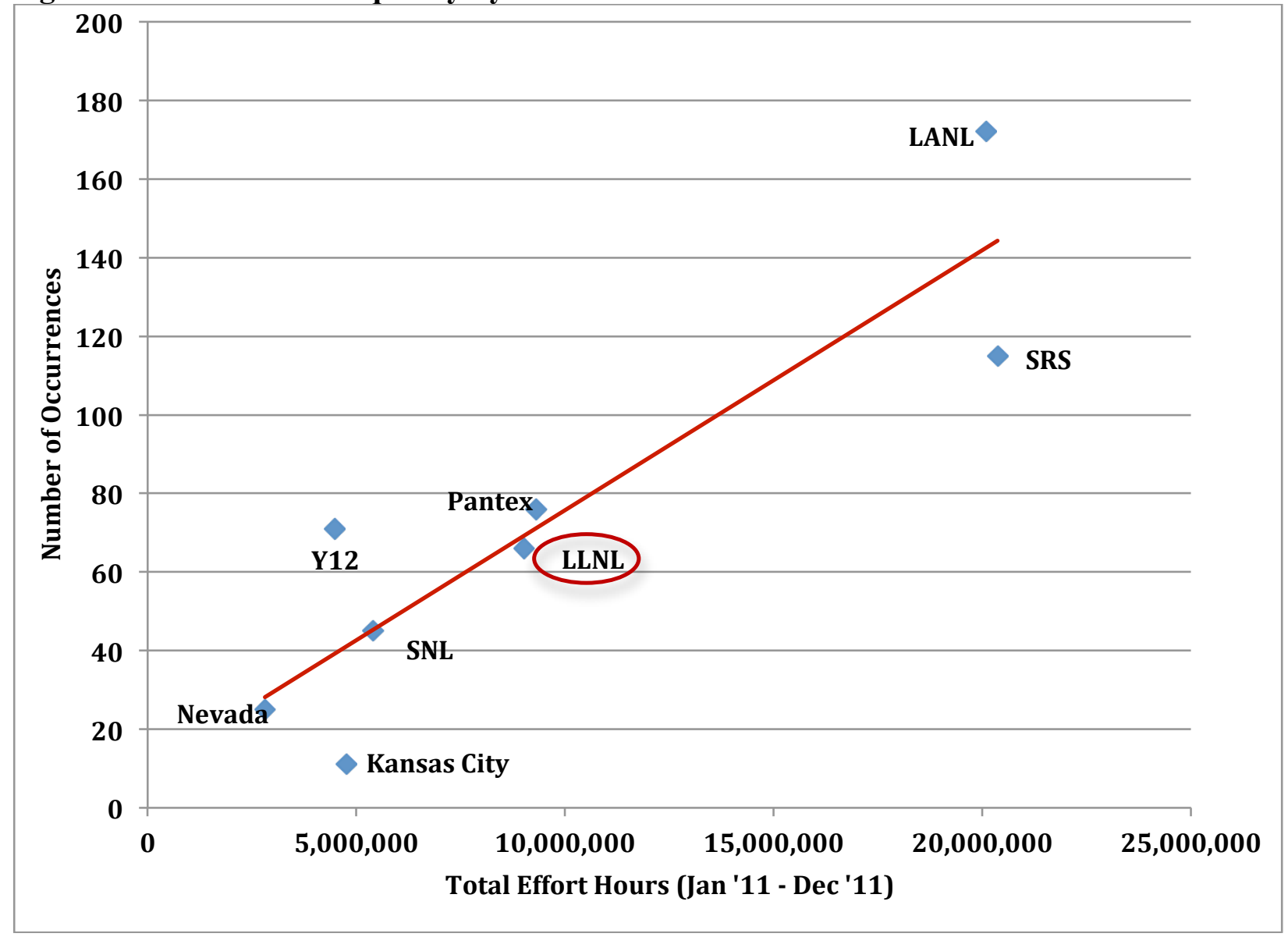

\subsection{Occurrence Reporting Group Comparison}


Occurrences within the DOE complex are categorized by reporting criteria groups. There are 10 major groups, as shown below:

Group 1 "Operational Emergencies"

Group 2 "Personnel Safety \& Health"

Group 3 "Nuclear Safety Basis"

Group 4 "Facility Status"

Group 5 "Environmental"

Group 6 "Contamination/Radiation Control"

Group 7 "Nuclear Explosive Safety"

Group 8 "Transportation"

Group 9 "Noncompliance Notifications"

Group 10 "Management Concerns"

In Figure 3, LLNL is compared to all DOE sites reporting occurrences in ORPS by reporting criteria group. Reporting criteria groups are displayed as percentages against the total number of occurrences.

Figure 3 - LLNL and DOE Complex Occurrence Reporting Group Comparison

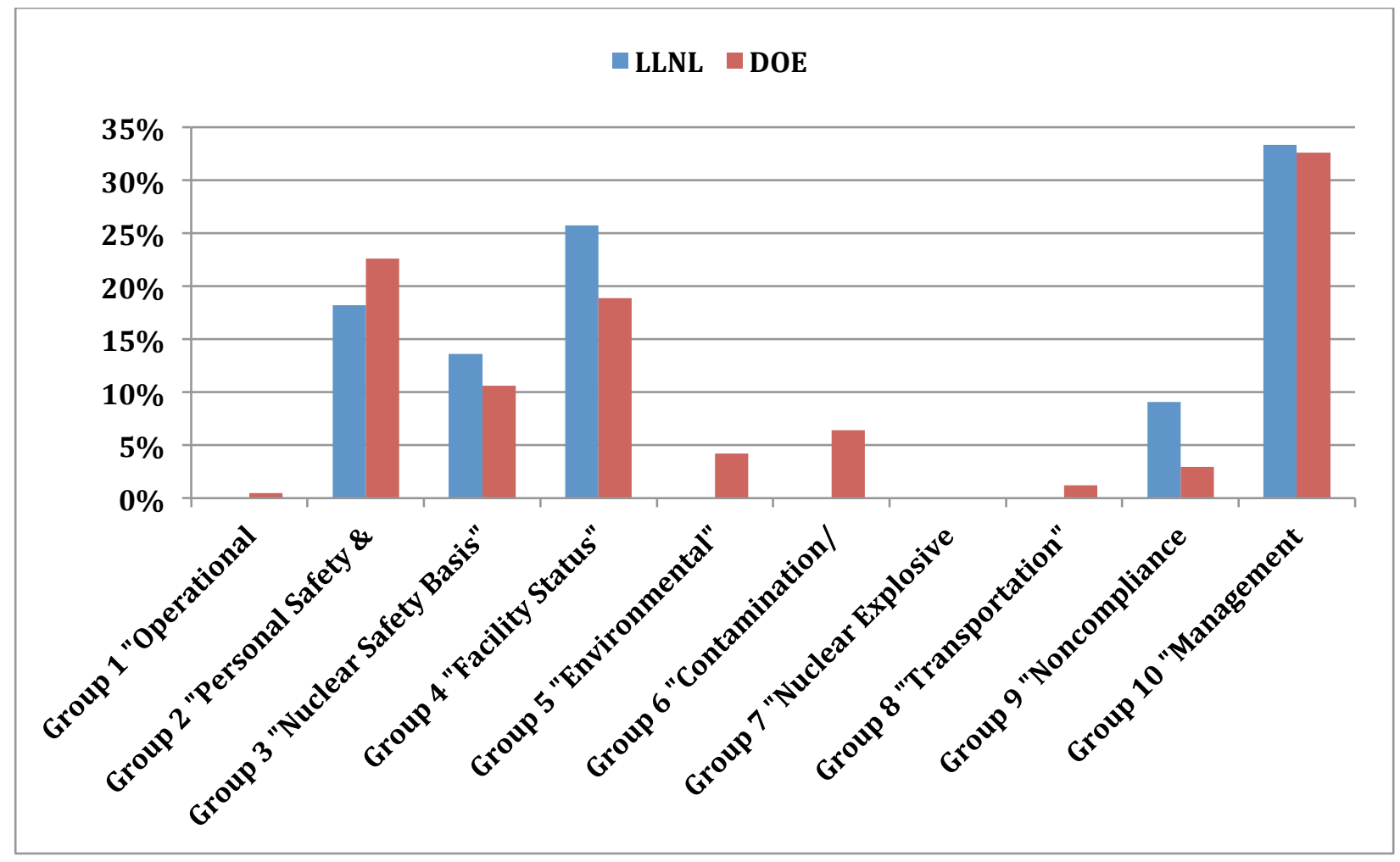

As can be seen from Figure 3, LLNL reported fewer events in all Groups except for Groups 3, 4, 9, and 10 than the rest of the DOE complex. As percentages of total reports, LLNL reported more "Nuclear Safety Basis," "Facility Status," "Noncompliance Notifications," and "Management Concerns" than did the rest of the complex. 
For the Group 3, "Nuclear Safety Basis," occurrences, two were Technical Safety Requirement Violations and seven were Potential Inadequacy of Safety Analysis.

For the Group 4, "Facility Status," occurrences, there were six events with degradations of Safety Significant equipment. Three of these events were due to failures of emergency battery lighting system lights and batteries (end of life failures), and do not represent a system deficiency. The directorate is replacing the lights and batteries upon finding them during their normal testing schedule; however, due to the way the occurrence reporting criteria is written, each failed light or battery prompts a mandatory occurrence report. The B332 DSA was updated and the Emergency Egress Light Battery (EELB) was downgraded from Safety Significant to Defense-In-Depth. LSO agreed to the justification of downgrading thus the DSA was updated to reflect the system change. Defense-in-depth items do not require filing an occurrence report when they fail during testing. There was one Group 4 occurrence related to failures of individual components of safety systems that resulted in degraded conditions when a fire barrier door in Building 331 would not latch. An additional degraded condition occurred when the air pressure in a bottle servicing a glovebox exhaust control panel was below the low pressure limit. A cracked glovebox window accounted for the final degraded condition. One occurrence resulted from the failed surveillance of a safety class pressure regulator on the fire suppression system in Building 332.

For the Group 9, "Noncompliance Notifications," there were six events in this period, compared with seven in the previous reporting period. Five non-compliances were for violations (mostly minor) of environmental regulations and one was for a lapse in the HSD medical X-ray registration. There is no adverse trend was noted for these events.

For Group 10, "Management Concerns," there was a slight increase in the number of events over the previous reporting period. 22 events occurred in this reporting period compared to 21 in the previous period. This does not represent a significant increase in management concerns.

As has been seen in previous reports, slightly under one-third of all DOE complex, and LLNL occurrences in this period were filed under the "Management Concern" (Group 10) reporting criteria. This is a consistent pattern for Group 10 reporting throughout DOE. LLNL reported no "Operational Emergencies" (Group 1), "Environmental" (Group 5), "Nuclear Explosive Safety" (Group 7) or "Transportation" (Group 8) occurrences in the period October 1, 2010 through September 30, 2011.

\subsection{Occurrence Significance Category Comparison With Other DOE Sites}

Occurrences within the DOE complex are assigned a significance category (SC), based on the severity of the event. There are six significance categories, as defined below:

Operational Emergencies (OE) - Operational Emergency Occurrences are the most serious occurrences and require an increased alert status for onsite personnel and, in specified cases, for offsite authorities. 
Significance Category R - Recurring occurrences are those identified as recurring, either directly or through periodic analysis of occurrences and other non-reportable events. A recurring occurrence is two or more events or conditions that are similar or have a common cause, that are identified over time and for which there has been opportunity to correct the initial event, condition or cause.

Significance Category 1 - Non-OE events that caused actual harm; posed the potential for immediate harm or mission interruption due to safety system failure and required prompt mitigative action; or constituted an egregious noncompliance with regulatory requirements that created the potential for actual harm or mission interruption.

Significance Category 2 - Circumstances that reflected degraded safety margins - necessitating prompt management attention along with modified normal operations - to prevent an adverse effect on safe facility operations; worker or public safety and health, including significant personnel injuries; regulatory compliance; or public/business interests.

Significance Category 3 - Events or circumstances with localized implications including personnel injury, environmental releases, equipment damage or hazardous circumstances that were locally contained and did not immediately suggest broader systemic concerns. Occurrences in this category are those that are not Operational Emergencies and that have a minor impact on safe facility operations, worker or public safety and health, regulatory compliance, or public/business interests.

Significance Category 4 - Events or circumstances that were mitigated or contained by normal operating practices, but where reporting provides potential learning opportunities for others. Occurrences in this category are those that are not Operational Emergencies and that have some impact on safe facility.

In Figure 4, LLNL is compared to all DOE sites reporting occurrences in ORPS, by reporting significance category. Reporting significance categories are displayed as percentages against the total number of occurrences. 
Figure 4 - Occurrence Significance Category Comparison: LLNL and DOE Sites

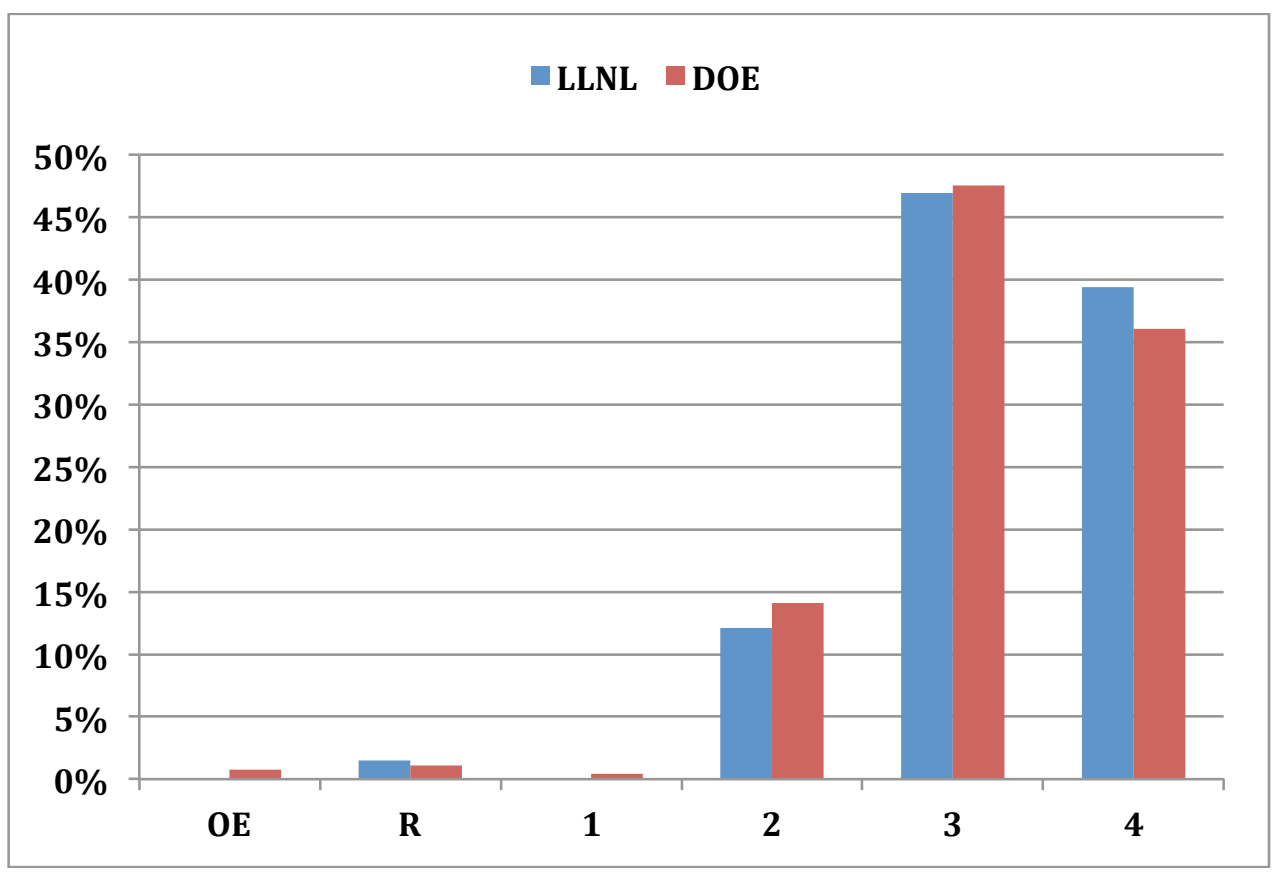

As can be seen from Figure 4, LLNL reported no occurrences in significance categories OE or 1 during this 12-month period. There was one $\mathrm{R}$ involving the failure to follow established lockout/tagout procedures. LLNL reported roughly 2\% less of SC 2 events; $1 \%$ less SC 3 events and 3\% more SC 4 events than did the rest of the DOE complex. For the period January 1, 2011 through December 31, 2011, LLNL reported 31 events in SC 3 representing 47\% of the total, and the rest of the sites reported 564 events in the category, or $48 \%$ of the total. As seen in previous reports, SC 3 comprises the largest percentage of both LLNL and DOE occurrences.

\subsection{Occurrences by Principal Directorate}

This section provides a representation of LLNL events reported to ORPS and other events not meeting the ORPS reporting thresholds, but deemed reportable at the "site" level (below-ORPS occurrences).

LLNL reported 66 occurrences to DOE during the period January 1, 2011 through December 31, 2011 , one less than during the previously analyzed 12-month period. The distribution of occurrences by the principal directorates is listed in Figure 5. 
Figure 5 - Total Occurrences by LLNL Principal Directorate

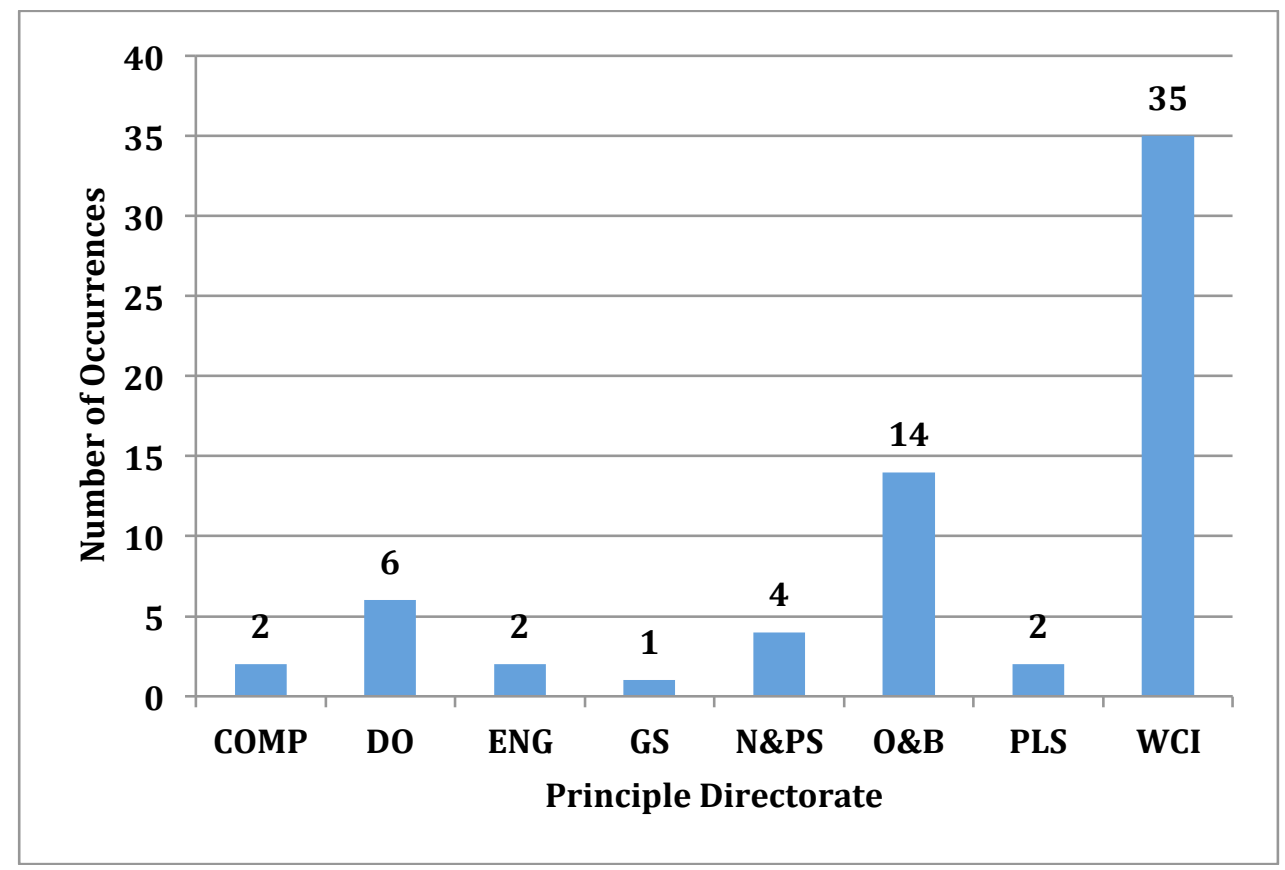

For January 1, 2011 through December 31, 2011, the following is observed:

- Computation directorate reported only two occurrences in this period.

- The Director's Office six occurrences, the same number as last period.

- Engineering reported two occurrences in this period, an increase of one over last period.

- Global Security reported only one occurrence in this period.

- N\&PS reported four events in this period, the same as the previous report.

- Operations and Business had a slight decrease in events, from 16 in the previous report to 14 in this period. Three of their events were of the Group 10, "Management Concern" type, seven were for personal safety and health, one was suspect counterfeit, and three were noncompliance notifications.

- Physical and Life Sciences reported two events in this period, compared to three events in the previous report.

- Weapons and Complex Integration reported 35 occurrences in this period, the same as last period. Nine of these events were in the Group 3 "Nuclear Safety Basis" area, 12 were in Group 4, "Facility Status"(five events were for suspect/counterfeit material, Group 4C), two were for notices of violation and twelve of these events were in Group 10, "Management Concern."

In order to better understand our event experience, we compared the 12-month data analyzed in this report to the preceding two 12-month periods: January 2009-December 2009; January 2010December 2010; and January 2011-December 2011. Figure 6 shows the comparison of the three 12-month periods with events by principle directorate. 
Figure 6 - LLNL Occurrences by Directorate in Three year periods: January 2009-December 2009, January 2010-December 2010, and January 2011-December 2011

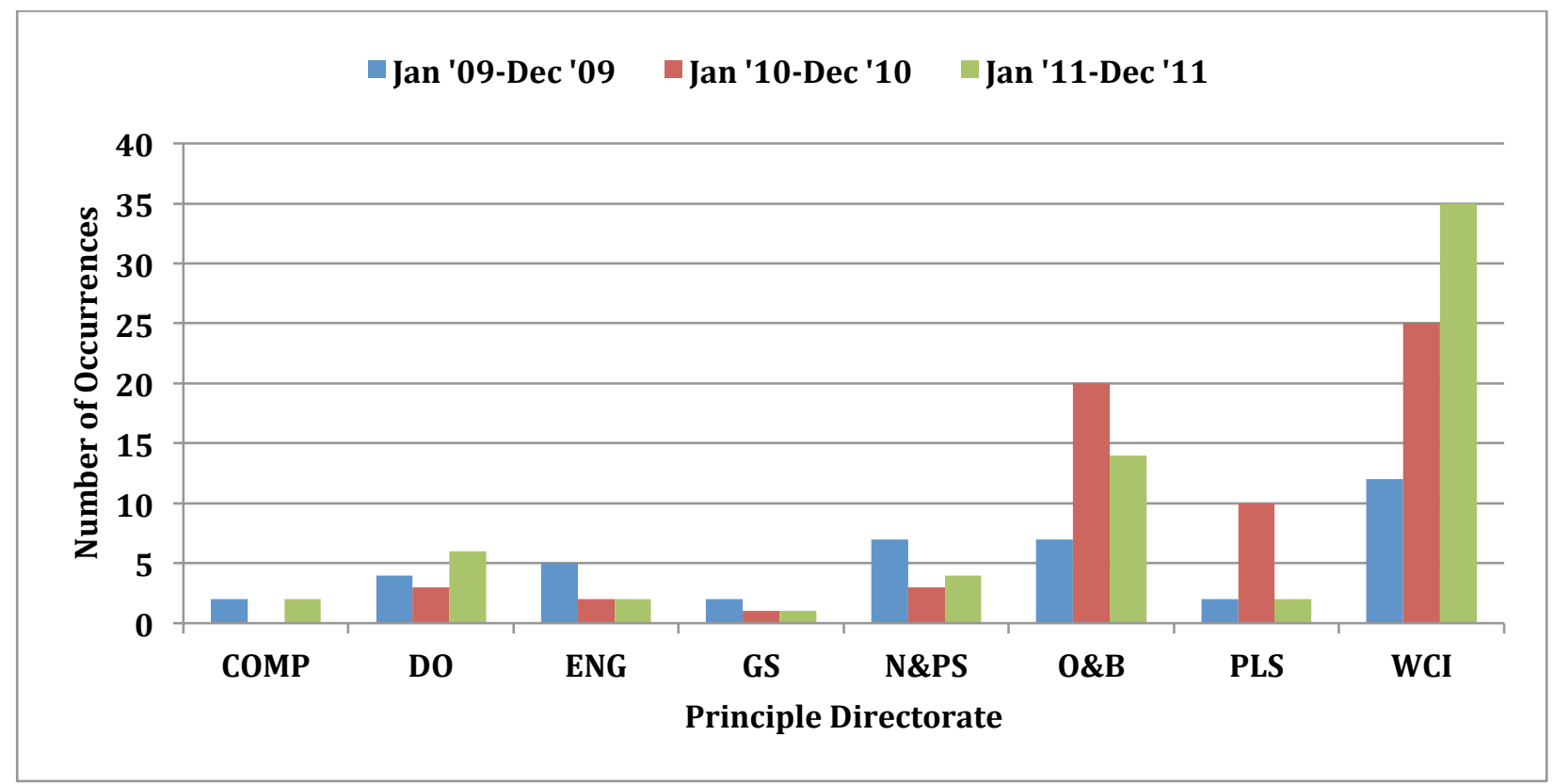

The graph indicates that WCI has had an increase. O\&B and WCI experienced the most events. Computation, Director's Office, Engineering, Global Security, NIF and Photon Science, and Physics and Life Sciences experienced significantly fewer events. WCI's event experience is mainly due to Nuclear Safety Basis (Group 3), Facility (Group 4) and Management Concern (Group 10) events. No negative trends are noted.

\subsection{Summary of LLNL Occurrences by Reporting Criteria Group}

In the DOE occurrence reporting system, there are 10 major reporting criteria groups, and 18 subgroups. The 66 occurrences, reported in the period January 1, 2011 through December 31, 2011, are divided among the reporting criteria groups discussed below.

- One occurrence in $\mathrm{O} \& \mathrm{~B}$ required reporting a recurring condition for not following lockout/tagout procedures.

- 12 occurrences were classified as "Personnel Safety \& Health" (Group 2) occurrences representing personal exposures, fractures, minor shocks, failure to control hazardous energy. The same number of Group 2 events reported in the previous report.

- Nine occurrences were classified as "Nuclear Safety Basis" (Group 3) occurrences representing technical safety requirement violations and Potential Inadequacies of Documented Safety Analyses (PISA). There were also nine Group 3 events reported in the previous report. 
- 17 occurrences were classified as "Facility Status" (Group 4) occurrences representing performance degradation or failed surveillance of facility safety systems, continuous air monitor (CAM) alarms, failure to follow proper procedures and discovery of Suspect/Counterfeit (S/CI) or defective items. There were also 17 Group 4 events reported in the previous report.

- Zero occurrences was classified as "Contamination/Radiation Control" (Group 6) representing spread of radioactive contamination above the limits in 10 CFR 835, Appendix D.

- Six occurrences were classified as a "Noncompliance" (Group 9) occurrences representing written notification of a noncompliance by an outside agency. There were seven Group 9 events reported in the previous report.

- 22 occurrences were identified as "Management Concerns" (Group 10) that did not meet the threshold of specific DOE reporting criteria. However, LLNL determined these occurrences to be significant and/or of value to share locally or complex-wide. There were 21 Group 10 events reported in the previous report.

Most of these events are the same as represented in the previous reporting period. 
Figure 7, below, shows the distribution of occurrences by reporting criteria group for this period. The totals are shown above the columns.

Figure 7 - LLNL Occurrences by Major Reporting Criteria Group for January-December 2011

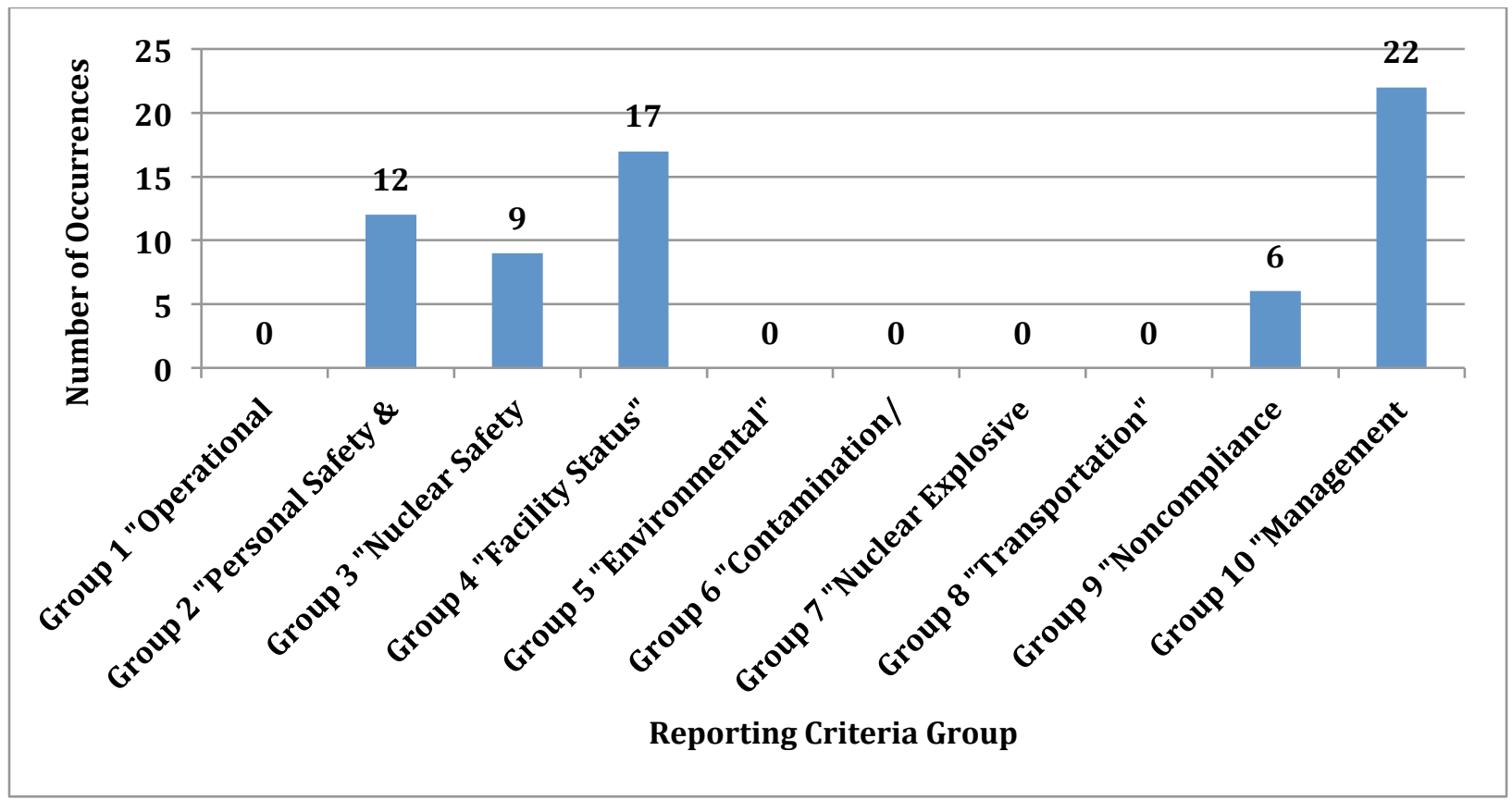

As stated earlier, we compared the 12-month data analyzed in this report (January-December 2011) to the preceding two years: January-December 2009; January-December 2010. 
Figure 8 shows the comparison of the three years with events by reporting criteria group.

Figure 8 - LLNL Occurrence Reports by Major Reporting Criteria Group for Three Years: January-December 2009; January-December 2010; and January-December 2011

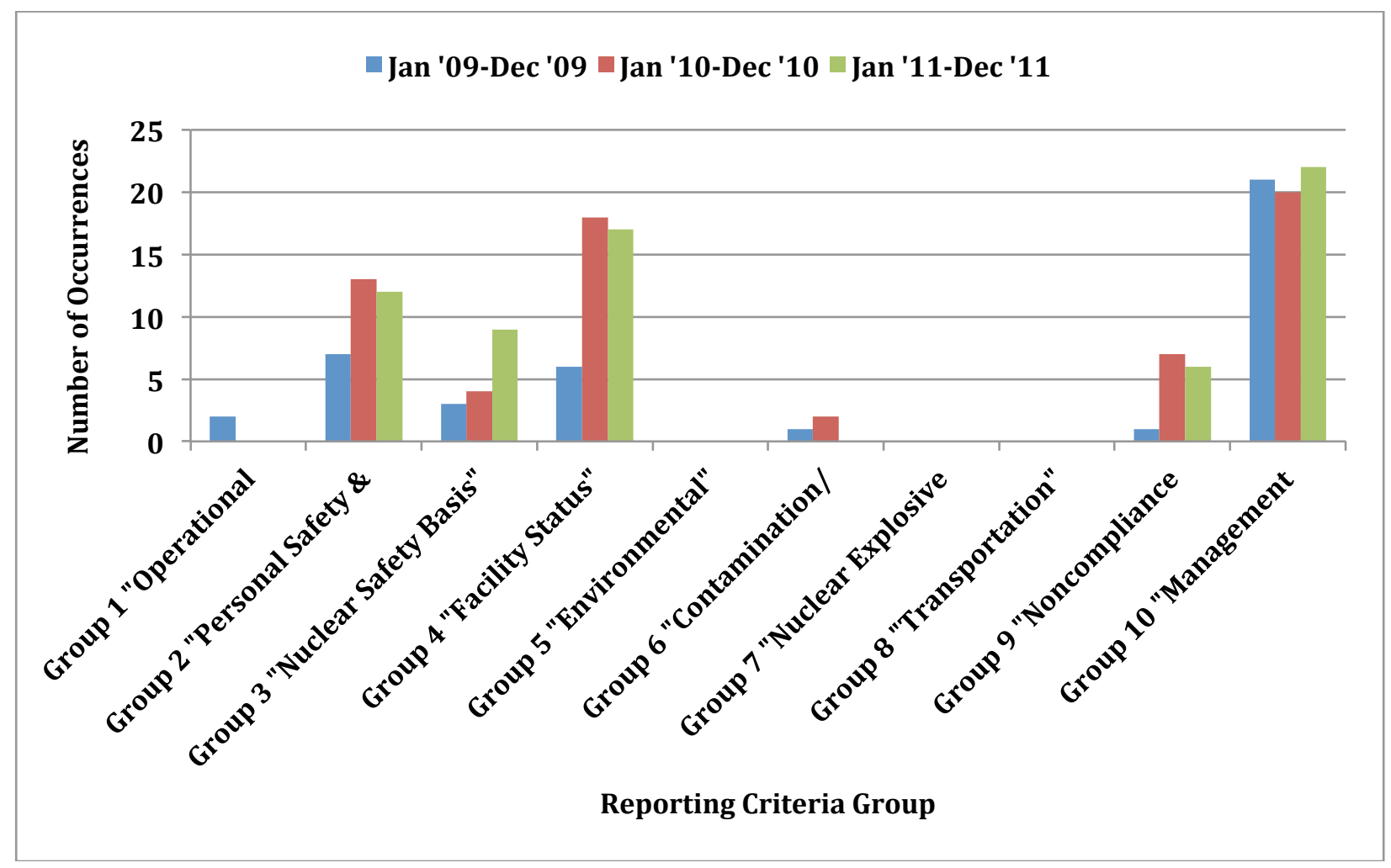

As can be seen in the Figure 8, there is variation between the periods, with respect to event reporting. For example, LLNL has not reported any Operational Emergencies (OE) since June 2009. There were two fires at Site 300 in 2009; a vegetation fire and a grassland fire. These fires had distinct causes, and do not represent a recurring condition. These fires were analyzed in previous reports. Another notable distinction can be seen in the number of occurrences from period to period. In the period January 2009-December 2009, there were significantly fewer events (represented in the blue bars on the graph) than years prior or since. Most Management Concern (10(2)) reports are from WCI/NMTP as encouraged by the DNFSB. The remainder of the data shows variation, but is not attributable to any negative trends. 


\subsection{Summary of LLNL Occurrences by Significance Category (SC)}

Occurrences are categorized by the level of consequence when reported. This significance category is defined by the DOE reporting criteria and determines the level of formality and rigor required in the response. SC 4 reports are considered "final" when they are entered initially and are not required to include the specific causes or corrective actions. The corrective actions are tracked in the LLNL issues tracking system.

The following describes the SCs reported for each of the 66 occurrences in this period:

- Less than $2 \%$ (1 out of 66 ) is reported as recurring (SC R)

- $12 \%$ (8 out of 66 ) were assigned as having a "moderate" impact (SC 2).

- $86 \%$ (57 out of 66 ) of the occurrences reported during this period were assigned at the lower level of consequence (SC 3 and 4) in ORPS having only "some" or "minor" impact on safe facility operations, worker or public safety and health, regulatory compliance, or public/business interests. This percentage is a slight decrease in the number of the SC3 and $\mathrm{SC} 4$ events reported in the previous report ( $88 \%)$.

- $47 \%$ (31 out of 66 ) reported as SC " 3 ," compared with 54\% from the previous report

- $39 \%$ (26 out of 66 ) reported as SC " 4 ," compared with $34 \%$ from the previous report

The distribution of LLNL occurrences by significance category is shown in Figure 9.

Figure 9 - LLNL Occurrence Reports by Significance Category (SC)

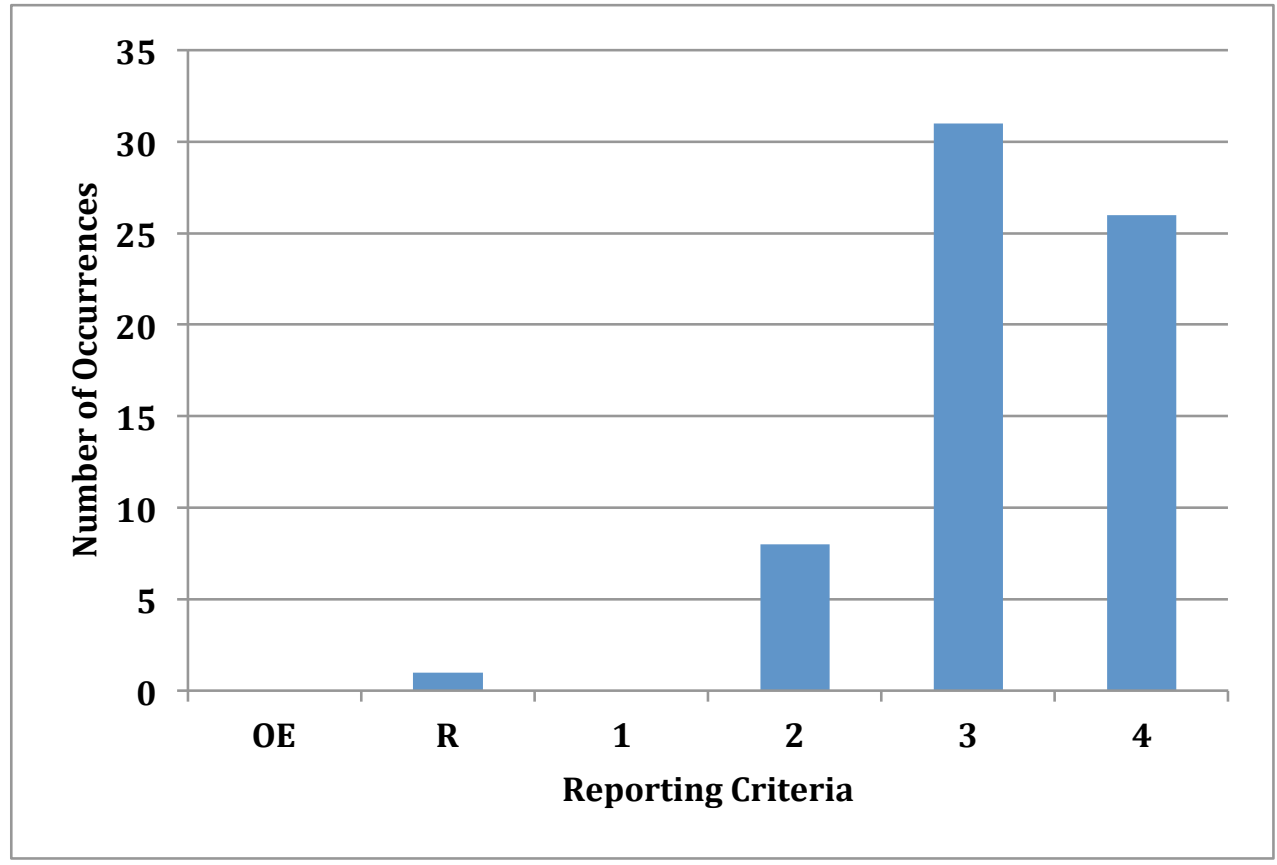


Almost one-half (31 out of 66 SCs assigned, or 47\%) of all events are categorized as SC 3. This percentage represents a slight decrease from last quarter with three quarters of data overlapping from previous years where the percentage of SC 3 reports was at 54\%. This fluctuation is not abnormal, and is seen in other reports.

\subsection{Below-ORPS (Site) Reportable Events}

Site-reportable events or conditions are below the DOE reporting criteria threshold but are within the criteria established by agreement between LLNL and LSO. Site-reportable events or conditions are analyzed for potential recurring problems. In January 2006, LLNL began gathering site-reportable information, using a list of 13 areas agreed upon by the NNSA Livermore Site Office and LLNL.

The data is tracked in LLNL databases, such as Occupational Accident Injury/illness Analysis Support Information System (OAASIS) and the Sample Tracking and Reporting (STAR) database, or from specific Functional Area Manager's logbooks. An individual directorate may report a site-reportable item as a single event or condition.

\section{Summary of Reported Below-ORPS Occurrences by Reporting Criteria Group}

Group 2 - "Personal Safety"

Group 2A OSHA Recordable Cases

- 103 recordable cases (Medical treatment, restricted workday and days away cases)

○ 24 days away cases, requiring 1,040 days away

○ 17 restricted workday cases, requiring 1,668 restricted workdays

Note - The number of days away or restricted days reported to CAIRS for any single case is limited to 180 . The numbers listed above are the total days away/restricted days as reported in OAASIS.

The full analysis of the injuries and illnesses for specific trends and common causes is provided in appendix A. This analysis was included in the Monthly Performance Review discussion.

Group 2B Measured Exposures

- 39 measured exposures above the action level

○ Silica - 22 measured exposures exceeding an action level; however, the workers were properly protected with respirators.

$\circ$ Noise - 15 measured exposures exceeding an action level; however, the workers were properly protected with respirators.

Group 2E \& 2F Hazardous Energy Control Process (Electrical and other)

- There were no events meeting this criteria

Group 2C Fire

- There were two fires reported to the fire department that took less than 10 minutes to put out, but the fire disrupted operations in moderate hazard facilities for this period. One occurred when wire insulation on a forklift in RHWM caught fire. The fire was 
immediately extinguished by on scene personnel using the fire extinguisher mounted on the forklift. The other fire occurred in pine needles outside Building 694. There were paper matches visible around that area of the fire, so it could have been started by a match not being completely out when discarded. It was extinguished with a bowl of water and the fire department responded and determined it was out.

Group 4 - "Facility Status"

There were six events that fall into this category:

Group 4A Performance Degradation of SSC

- There was one event meeting this criteria - a Building 235, Room 1130 CAM unit presented a fault indication. This was one of two CAMs in the room, and although there was no alarm, it was required to be operable. This is a non-nuclear facility. This event was reported in the previous report.

Group 4C Violation of FSP/OSP/IWS or working without authorization

- Five events were related to working in violation of Facility Safety Plans, Operational Safety Plans or Integration Work Sheets/Safety Plans (FSP/OSP/IWS/SP), or working without proper authorization. No trend was noticed for the violations.

Group 5 - "Environmental"

- There were 18 instances of hazardous liquids and/or untreated water, treated water and water containing low concentrations of inhibitors or biocides released to the environment during the review period. The most significant releases were 6600 gallons of potable water to a storm drain, 5000 gallons of irrigation water near Building 123, 2000 gallons of water near bunkers 850 and 851, and 6000 gallons of irrigation water discharged into a landscape area. Two were reported to the regional water quality control board in nonroutine reports.

Group 6 - "Radiation"

- There were a total of 20 CAM (Continuous Air Monitor) alarms received in the review period.

○ 1 alarm due to plutonium

- 20 alarms were from radon sources

- 1 alarm due to non-radiological activity

- There were 3 TAM (Tritium Air Monitor) alarms due to non-radiological activity

- There were no positive nasal swipe readings

Group 8 - "Transportation"

- There were no transportation events reported during the review period

Below-ORPS events have also been analyzed in other analysis reports, such as, The Performance Analysis of Bicycle Accidents 2008-2010 report dated 1/11/2011, and the Performance Analysis: Issues Tracking System Data through December 2010 report dated July 2011. 


\section{Appendix A}

\section{ES\&H \\ Injury and Illness Annual Report - 2011}




\section{Injury and IIIness Annual Report - 2011}

This is a summary of LLNLs work-related injury and illness cases for 2011. Some terms used in this report include

TRC Total Recordable Cases; an OSHA term for injuries requiring medical treatment beyond first aid.

DART Days Away and Restricted Time; the sum of lost workday and restricted workday cases.

DAC Days Away Cases.

Severity The sum of days away and restricted days for a given case or organization.

Case rates are calculated from the number of each type of case; normalized over 100 FTE. This allows relative comparisons between organizations.

\section{LLNL Injury and IIIness Rates - Calendar Year 2011}

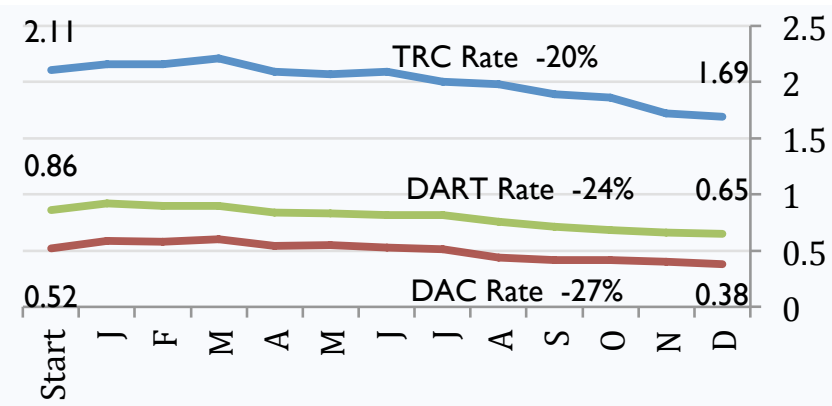

During this period while the number medical treatment cases went down, the number of visits to the Health Services clinic remained constant. This would indicate that workers are reporting their injuries, with the end result of minimal treatment or evaluation only.

\section{Case Attribution by Work and Payroll Lines}

In FY '11, LLNL started dual line tracking of injury cases. Cases and the associated effort hours were assigned to the organization responsible for directing the work activity in progress.

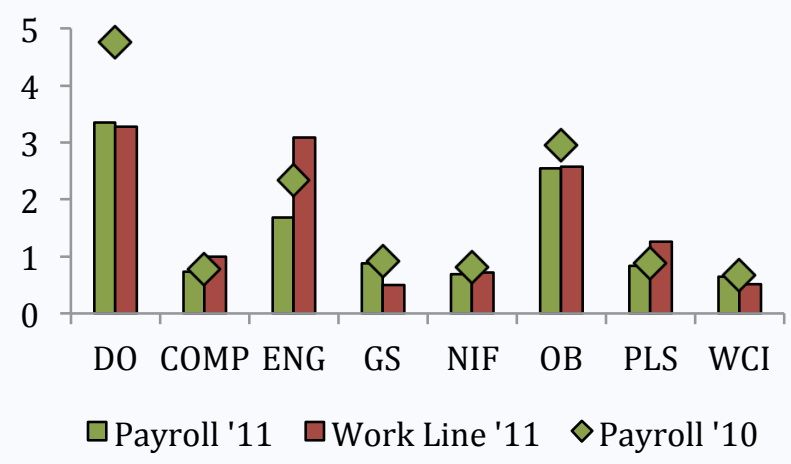

Perspective on LLNL Injury and IIIness Rates - September 30, 2007 to December 31, 2011

Since contract transition injury rates have declined, yet fluctuations are evident. No seasonal pattern of rate change has been identified. While the TRC trend line shows a clear down slope, the DAC rate trend is flat. This may represent variations around a norm that is not easily reduced. Reviewing older data is not directly applicable due to its inclusion of the former Fire Department in the LLNL statistics.

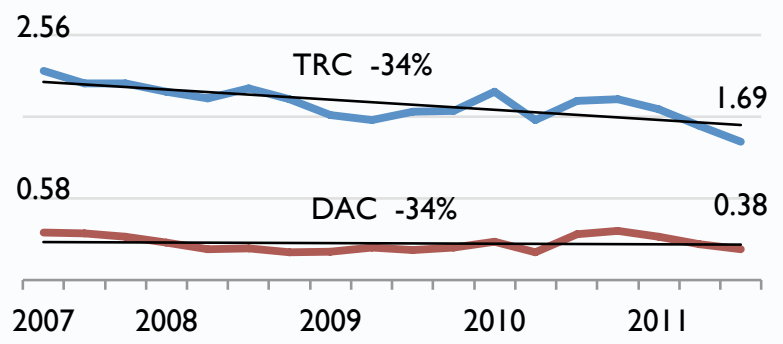

\section{Activities Leading to Injuries}

The following tables show the predominant types of injuries and illnesses and severity resulting from different activities. These data are since October 1, 2007.

\section{Percent of All Injury Types by Activity- Frequency}

Activities are rank ordered by frequency of injuries.

\begin{tabular}{llllll} 
& $\begin{array}{l}\text { Strain/ } \\
\text { Sprain }\end{array}$ & MSD/CT & $\begin{array}{l}\text { Hearing } \\
\text { Loss }\end{array}$ & Cuts & $\begin{array}{l}\text { Other } \\
\text { Types }\end{array}$ \\
\hline Office & 18 & 70 & & 1 & 10 \\
Maint/Const & 27 & 6 & 32 & 13 & 22 \\
Mat'l & 64 & 13 & & 7 & 15 \\
Handling & 56 & 4 & 12 & 8 & 21 \\
Security & 38 & & & 10 & 521 \\
Transit & 18 & 32 & 23 & 14 & 14 \\
Production & 18 & 12 & & 27 & 12 \\
Research & 41 & 28 & 3 & & 24 \\
All other & 45 & & & & \\
\hline
\end{tabular}

I. Fractures are $17 \%$ of all transit injuries.

Injury Outcomes by Activity- Severity

Activities are rank ordered by lost workdays.

\begin{tabular}{lllll} 
& $\begin{array}{l}\text { Lost } \\
\text { Workday } \\
\text { Cases }\end{array}$ & $\begin{array}{l}\text { Sum of } \\
\text { Lost } \\
\text { Days }\end{array}$ & $\begin{array}{l}\text { Restricted } \\
\text { Workday } \\
\text { Cases }\end{array}$ & $\begin{array}{l}\text { Sum of } \\
\text { Restricted } \\
\text { Days }\end{array}$ \\
\hline Office & 35 & 2417 & 5 & 990 \\
Security & 19 & 809 & 18 & 1541 \\
Maint/Constr & 17 & 758 & 12 & 1333 \\
Mat'l Handling & 15 & 507 & 18 & 1573 \\
Transit & 11 & 396 & 3 & 230 \\
Transportation & 5 & 149 & 2 & 167 \\
Production & 4 & 139 & 1 & 71 \\
Custodial & 3 & 102 & 4 & 402 \\
Research & 3 & 88 & 2 & 309 \\
\hline All LLNL & 112 & 5365 & 65 & 6616 \\
\hline
\end{tabular}





\section{Rate and Trend Analyses}

Data are valid as of January 9, 2012. Cases are tracked for five years, so the shown values will change.

Payroll Cases (Work line case data is not yet available)

\begin{tabular}{|c|c|c|c|c|c|}
\hline & Start & End & Change & High & Low \\
\hline \multicolumn{6}{|l|}{ All LLNL } \\
\hline TRC & 2.11 & 1.69 & $-20 \%$ & 2.21 & 1.69 \\
\hline DAC & 0.52 & 0.38 & $-27 \%$ & 0.60 & 0.38 \\
\hline DART & 0.86 & 0.65 & $-24 \%$ & 0.92 & 0.65 \\
\hline Severity & 62.72 & 41.2 & $-34 \%$ & 71.96 & 41.2 \\
\hline LD & 1442 & 1040 & $-28 \%$ & 1608 & 1040 \\
\hline RD & 2297 & 1548 & $-33 \%$ & 2680 & 1040 \\
\hline \multicolumn{6}{|l|}{ COMP } \\
\hline TRC & 0.77 & 0.73 & $-5 \%$ & 0.77 & 0.38 \\
\hline DAC & 0.13 & 0.24 & +85 & 0.25 & 0.12 \\
\hline DART & 0.64 & 0.37 & $-42 \%$ & 0.64 & 0.12 \\
\hline Severity & 17.96 & 15.26 & $-15 \%$ & 17.96 & I.II \\
\hline LD & 4 & 36 & $+800 \%$ & 4 & 36 \\
\hline RD & 136 & 89 & $-35 \%$ & 136 & 0 \\
\hline \multicolumn{6}{|l|}{ DO } \\
\hline TRC & 4.76 & 3.35 & $-30 \%$ & 4.76 & 3.35 \\
\hline DAC & 1.5 & 0.94 & $-37 \%$ & 1.76 & 0.94 \\
\hline DART & 2.18 & 1.74 & $-20 \%$ & 2.44 & 1.62 \\
\hline Severity & 155.67 & 104.44 & $-33 \%$ & 199.99 & 104.44 \\
\hline LD & 398 & 392 & $-2 \%$ & 606 & 392 \\
\hline RD & 747 & 387 & $-48 \%$ & 870 & 387 \\
\hline \multicolumn{6}{|l|}{ ENGR } \\
\hline TRC & 2.34 & 1.68 & $-28 \%$ & 2.41 & 1.68 \\
\hline DAC & 0.44 & 0.58 & $+32 \%$ & 0.58 & 0.21 \\
\hline DART & 0.66 & 0.19 & $-71 \%$ & 0.72 & 0.19 \\
\hline Severity & 59.87 & 14.93 & $-75 \%$ & 60.28 & 14.93 \\
\hline LD & 246 & 115 & $-53 \%$ & 246 & 83 \\
\hline RD & 574 & 98 & $-83 \%$ & 612 & 98 \\
\hline \multicolumn{6}{|l|}{ GS } \\
\hline TRC & 0.93 & 0.88 & $-5 \%$ & 1.38 & 0.71 \\
\hline DAC & 0.46 & 0 & $-100 \%$ & 0.46 & 0 \\
\hline DART & 0.46 & 0 & $-100 \%$ & 0.46 & 0 \\
\hline Severity & 83.55 & 0 & $-100 \%$ & 83.55 & 0 \\
\hline LD & 134 & 0 & $-100 \%$ & 134 & 0 \\
\hline RD & 36 & 0 & $-100 \%$ & 46 & 0 \\
\hline \multicolumn{6}{|l|}{ NPS } \\
\hline TRC & 0.81 & 0.69 & $-15 \%$ & 0.81 & 0.69 \\
\hline DAC & 0 & 0 & NA & 0 & 0 \\
\hline DART & 0 & 0 & NA & 0.2 & 0 \\
\hline Severity & 5.27 & 0 & $-100 \%$ & 5.27 & 0 \\
\hline LD & 0 & 0 & NA & 0 & 0 \\
\hline RD & 26 & 0 & $-100 \%$ & 26 & 0 \\
\hline \multicolumn{6}{|l|}{ OB } \\
\hline TRC & 2.96 & 2.63 & $-11 \%$ & 3.56 & 2.63 \\
\hline DAC & 0.7 & 0.75 & $+7 \%$ & 1.16 & 0.7 \\
\hline DART & 1.25 & 1.2 & $-4 \%$ & 1.78 & I. 14 \\
\hline Severity & 105.16 & 99.18 & $-6 \%$ & 157.49 & 98.55 \\
\hline LD & 598 & 452 & $-24 \%$ & 793 & 452 \\
\hline RD & 752 & 868 & $+15 \%$ & 1243 & 752 \\
\hline \multicolumn{6}{|l|}{ PLS } \\
\hline TRC & 1.53 & 0.95 & $-38 \%$ & 1.53 & 0.84 \\
\hline DAC & 0.31 & 0.12 & $-61 \%$ & 0.38 & 0.12 \\
\hline DART & 0.54 & 0.12 & $-78 \%$ & 0.54 & 0.12 \\
\hline Severity & 9.48 & 9.37 & $-1 \%$ & 19.41 & 9.37 \\
\hline LD & 59 & 45 & $-24 \%$ & 145 & 45 \\
\hline RD & 16 & 34 & $+113 \%$ & 320 & 16 \\
\hline \multicolumn{6}{|l|}{$\mathbf{W C I}$} \\
\hline TRC & 0.68 & 0.65 & $-4 \%$ & 1.02 & 0.65 \\
\hline DAC & 0.34 & 0 & $-100 \%$ & 0.34 & 0 \\
\hline DART & 0.34 & 0.33 & $-3 \%$ & 0.34 & 0 \\
\hline Severity & 1.03 & 23.44 & $+2176 \%$ & 24.15 & 0 \\
\hline LD & 3 & 0 & $-100 \%$ & 3 & 0 \\
\hline RD & 0 & 72 & $+100 \%$ & 72 & 0 \\
\hline
\end{tabular}

*These data, and more, are at

https://biweb.1lnl.gov/pls/lb/oaasis.oa_all_rates_pg2.oa_get_all_rates_prm_pr1
Reviews of available data produced these observations:

- Over the past five years, the average LLNL rates are higher than the DOE and NNSA averages and most of the comparable contractors.

- LLNL rates by operation type - research, plant services, and security - are higher than the DOE averages for like work.

- Comparisons between DOE major sites is complicated by the degree of subcontracted work, operation types (including type of protective forces), and state-to-state worker's compensation regulations.

- WAL A activities account for $56 \%$ of injuries, WAL B and C activities have $44 \%$.

- The distribution of injury frequency by age group closely matches the number of workers in each age group. The median age of injured workers is exactly the same as the median age of the Lab's workforce (48.6).

- The gender differences in injuries by severity and activity usually is related to the relative sizes of the workforce performing different tasks, e.g. office, material handling. The rate of injuries occurring to females during transit is disproportionally high.

\section{Upcoming Injury and Illness Activities}

Rate Reduction Efforts

LLNL has launched a kinesiology-based training program, MoveSMART, to address the ongoing frequency of musculoskeletal injuries. Target groups with high risk of injury have been identified. The effect of training completions on rate reduction will be monitored and regularly reported as an ISO 18001 metric.

Injuries due to repetitive motion and cumulative trauma are being addressed by increased ergonomic evaluations in all the Directorates. This is also a key metric for the 18001 certification.

\section{Case Analysis Streamlining and Consistency}

Two activities are underway to improve the quality of eCAR case files and to reduce the effort consumed when preparing them. One will use 6 Sigma tools to evaluating the possible benefits of a graded approach to case analysis. Currently LLNL evaluates all worker visits to Health Services in the same manner. The 6 sigma analysis is examining the benefits of more detailed investigations for high risk events, and reduced investigations for low risk, low consequence events.

The other eCAR improvement activity is being lead by the Worker Safety and Health Functional Area. This effort will address consistency in case reports; more detailed analysis of causes, including work planning; and corrective actions to prevent recurrence.

This report was prepared by the ES\&H Injury and IIIness Analysis Office. Contact Jerry Schweickert at ext 2-5267 or schweickert1@llnl.gov for additional information. 